VOLUME 74

(Whole No. 717)
NUMBER 6 NOVEMBER, 1968

\title{
BULLETIN of the
}

\section{American Mathematical Society}

\author{
Edited by \\ GIAN-CARLO ROTA M. H. PROTTER \\ MURRAY GERSTENHABER
}

Published by the American Mathematical Society

PROVIDENCE, RHODE ISLAND 


\section{AMERICAN MATHEMATICAL SOCIETY}

General Office: P.O. Box 6248, Providence, Rhode Island 02904

Executive Director: G. L' Walker

Officers:

President: Professor C. B. Morrey, Department of Mathematics, University of Californa, Berkeley, California 94720.

President Elect: Oscar Zariski, Department of Mathematics, Harvard University, Cambridge, Massachusetts 02138.

Secretary: Professor Everett Pitcher, Department of Mathematics, Lehigh University, Bethlehem, Pennsylvania 18015.

Treasurer: Professor W. T. Martin, Department of Mathematics, Massachusett Institute of Technology, Cambridge, Massachusetts 02139.

Associate Secretaries:

Professor P. T. Bateman, Department of Mathematics, University of Illinois, Urbana, Illinois 61803 .

Professor Herbert Federer, Department of Mathematics, Brown University, Providence, Rhode Island 02912.

Professor O. G. Harrold, Department of Mathematics, Florida State University, Tallahassee, Florida 32306.

Professor R. S. Pierce, Department of Mathematics, University of Washington, Editors: Seattle, Washington 98105

Executive Editor of Mathematical Reviews: Richard Crittenden, 416 Fourth Street, Ann Arbor, Michigan 48103.

Editor of Translations Projects: S. H. Gould, P.O. Box 6248, Providence, Rhode Island 02904

Managing Editor of the Bulletin: Professor Murray Gerstenhaber, Department of Mathematics, University of Pennsylvania, Philadelphia, Pennsylvania 19104

Managing Editor of the Proceedings: Professor A. P. Mattuck, Department of Mathematics, Massachusetts Institute of Technology, Cambridge, Massachusetts 02139.

Managing Editor of the Transactions: Professor Dana Scott, Department of Mathematics, Stanford University, Stanford, California 94305.

Chairman, Mathematical Reviews Editorial Committee: Professor Paul R. Halmos, Department of Mathematics, University of Michigan, Ann Arbor, Michigan 48104

Chairman, Colloquium Editorial Committee: Professor George Mackey, Department of Mathematics, Harvard University, Cambridge, Massachusetts 02138

Chairman, Mathematical Surveys Committee: Bertram Yood, Department of Mathematics, University of Oregon, Eugene, Oregon 97403.

Chairman, Mathematics of Computation Editorial Committee: Professor Eugene Isaacson, University Computing Center, Courant Institute of Mathematical Sciences, New York University, New York, New York 10012.

Representatives of the Society on the Board of Editors of the American Journal of Mathematics:

Professor Stephen Smale, Department of Mathematics, University of California, Berkeley, California 94720

Professor G. D. Mostow, Department of Mathematics, Yale University, New Haven, Connecticut 06520.

The annual dues of members of the Society are $\$ 20.00$, payable to the American Mathematical Society, P.O. Box 6248, Providence, Rhode Island 02904.

The Bulletin of the American Mathematical Society is published bimonthly, in January, March, May, July, September, and November. Price per annual volume is $\$ 12.00$ Subscriptions, orders for back numbers, and inquiries in regard to nondelivery of current numbers should be addressed to the American Mathematical Society, P.O Box 6248, Providence, Rhode Island 02904.

Second-class postage paid at Providence, Rhode Island and additional mailing offices. Acceptance for mailing at the special rate of postage provided for in the act of February 28, 1925, embodied in paragraph 4, Section 538, P. L. and R., authorized May 9, 1935. 